\title{
Open-field behavior of young chicks (Gallus gallus): Antipredatory responses, social reinstatement motivation, and gender effects
}

\author{
GIORGIO VALLORTIGARA and MARIO ZANFORLIN \\ Università di Padova, Padova, Italy
}

\begin{abstract}
Two experiments investigating sex differences in the open-field behavior of young chicks are reported. In the first experiment, ambulation latencies of 10-day-old male and female chicks in a novel environment were measured. Half of the chicks were kept in social isolation for 2 days prior to testing; the other half were socially reared until tested. Results showed that in socially reared chicks ambulation latencies were significantly higher in males than in females, whereas in isolation-reared chicks there were no significant sex differences. In the second experiment, latencies of ambulation were measured in socially reared 10-day-old chicks placed in a novel en. vironment with or without a visible predator (i.e., a human being). Sex differences were evident in both conditions, with males showing higher ambulation latencies than females. It is argued that sex differences in open-field behavior of chicks may be due to a stronger motivation for social reinstatement in females, which reduces the usual antipredatory reactions of chicks placed in a novel environment.
\end{abstract}

Contradictory results have been reported conceming the existence of sex differences in the open-field behavior of young chicks. Candland, Nagy, and Conklyn (1963) found no significant sex differences in the distress calling of 1 day-old chicks, and Gallup (1974) reported no sex differences in tonic immobility. Faure and Folmer (1975) and Faure (1979) reported sex differences in only one of 13 strains tested. Consistent sex differences, however, have been reported by Jones and his co-workers: males show less activity, vocalization, and feeding (Jones, 1977a, 1977b; Jones \& Black, 1979), and emerge more slowly from a dark enclosure (Jones, 1979). These observations were recently confirmed by Jones and Faure $(1981,1982)$, who argued that previous contradictory results could be due to differences in the open fields used, which may have induced differing levels of fear depending on how similar they were to the chicks' home cage. These authors maintain that (1) males are more fearful than females, and (2) sex differences that appear at low-to-moderate levels of fear may disappear at higher levels of fear.

What remains unclear, however, is what the functional explanation for these differences may be: why should males be more fearful than females? A possible explanation may be related to the different interpretative approach of open-field behavior recently proposed by Gallup and Suarez (1980). Gallup and Suarez proposed that, as opposed to a "fear" or "emotionality" hypothesis, openfield behavior might reflect a compromise between opposite tendencies to reinstate social contact with conspecifics and to evade predation. Indeed, almost all open-

Reprint requests should be directed to G. Vallortigara, Dipartimento di Psicologia Generale, Università di Padova, Piazza Capitaniato 3, 35139 Padova, Italy. field experiments involve predatory overtones related to the human contact resulting from the handling associated with the removal of the animal from its home cage and its subsequent placement in the testing apparatus (Suarez \& Gallup, 1981). Moreover, open-field testing also usually involves sudden social separation from familiar and/or imprinted companions (Suarez \& Gallup, 1983, 1985).

The importance of threats of predation and social isolation may differ for males and females. If one considers that male chicks develop into territorial and aggressive animals (McBride \& Foenander, 1962), it is reasonable to suppose that males might be "less social" than females. Gallup and Suarez (1980) observed that when faced with the threat of predation under natural conditions, young precocial birds typically freeze and do not emit calls. On the other hand, when faced with the threat of social isolation, birds emit distress calls and move about in the environment in order to reinstate social contact with the mother hen or imprinted companions.

According to Gallup and Suarez (1980), one can assume that (1) ambulation and distress-calling latencies of chicks in an open field are either an expression of the need for social reinstatement or an antipredatory reaction, and (2) there is a dynamic interaction and variable balance between the need for social reinstatement and the antipredatory reaction. Thus, the reported sex differences in the open-field behavior of chicks (i.e., the females move and emit distress calls faster than the males; Jones, 1977b) might represent (1) stronger antipredatory reactions in males than in females, (2) stronger tendencies to reinstate social contact with cage companions in females than in males, (3) some combination of both. Gallup and Suarez (1980; Suarez \& Gallup, 1982) have provided empirical evidence that the levels of the need for social reinstate- 
ment and the antipredatory reaction can be effectively manipulated using two empirical variables: social isolation and the presence/absence of a predator. Therefore, the aim of this paper was to determine, in two separate experiments, whether social isolation and the presence/absence of a predator could affect sex differences in ambulation latencies of chicks in an open field.

\section{EXPERIMENT 1 EFFECTS OF SOCIAL ISOLATION}

If the motivation for social reinstatement is stronger in females than in males, the reported shorter latencies of ambulation of females might reflect the fact that the usual antipredatory reactions are reduced because the need to reinstate social contact with cage companions is particularly strong. A simple way to reduce the motivation for social reinstatement is to isolate animals for several days prior to testing in the open field. Gallup and Suarez (1980) reported that, as a consequence of habituated social reinstatement tendencies, birds kept in social isolation for 2 days prior to testing showed significantly longer durations of freezing. This seems to suggest that a reduction in the motivation for social reinstatement enhances antipredatory reactions. If sex differences in chicks are due only to differences in the motivation for social reinstatement, then one can expect that sex differences in chicks isolated for some days prior to testing would disappear (or be considerably reduced). However, if there are sex differences in antipredatory reactions (or differences in antipredatory reactions accompanied by differences in the motivation for social reinstatement), then sex differences may appear in isolated chicks as well; in this event, no straightforward conclusions can be drawn.

\section{Method}

Subjects. The subjects were autosexed commercial hybrid chicks "Hybro" (a local variety derived from White Leghorn) obtained from a commercial incubator when they were only a few hours old. These chicks were reared socially in groups of 10 (see Apparatus and Procedure), in a controlled temperature of $30^{\circ} \mathrm{C}$, with food and water available ad lib. The rearing cages, $45 \times 25 \times 35 \mathrm{~cm}$, were illuminated by neon lamps, and an artificial cycle of $14 \mathrm{~h}$ light and $10 \mathrm{~h}$ dark was provided.

Apparatus and Procedure. The open field was a rectangular, $60 \times 30 \times 40 \mathrm{~cm}$ cage, which was placed in a soundproof room and illuminated from above by a $60-W$ electric light bulb. A unidirectional screen allowed the experimenter to observe the chick without being seen. Each chick was tested individually and once only. All tests were conducted on the 10th day of life between 0900 and $1300 \mathrm{~h}$. The chick was carried gently to the testing room and placed in the center of the open field. Latencies of ambulation were recorded, using a chronometer, over a 3 -min period following introduction of the chick into the open field.

A group of 30 animals (15 males and 15 females) were socially isolated in single cages (visually, but not acoustically, isolated from each other) for the 2 days preceding testing. A second group of 30 animals were socially reared in groups of 10 until they were individually tested. The experimenters were unaware of the sex of the chicks during testing.

\section{Results}

The results are illustrated in Figure 1. A $\log (x+1)$ transformation was performed to minimize heterogeneity of variance. A subsequent $2 \times 2$ analysis of variance revealed that the main effect of rearing conditions was significant $[F(1,56)=8.68, p=.004]$, as was the main effect of $\operatorname{sex}[F(1,56)=4.22, p=.042]$. The interaction of rearing conditions and sex was also significant $[F(1,56)$ $=4.97, p=.028$ ]. Paired $t$ tests revealed that males showed higher ambulation latencies among the socially reared chicks $[t(56)=3.14, p<.01]$ but not among the chicks isolated for 2 days prior to testing $[t(56)=.083]$.

\section{EXPERIMENT 2 \\ EFFECTS OF THE PRESENCE/ABSENCE OF A PREDATOR}

The results of Experiment 1 seemed to indicate that sex differences in the motivation for social reinstatement could be the main cause for the lower latencies of ambulation in the fernales. Indeed, when chicks are accustomed to social isolation-and therefore responses to the novel environment would be only antipredatory ones-sex differences in latencies of ambulation disappear. As a further test, we decided to determine whether an enhancement of the predatory overtones of open-field testing would affect sex differences. Suarez and Gallup (1982) had shown that the mere presence of a human seated in front of the open field during testing increases ambulation latencies in chicks, and that chicks respond to humans in much the same way as they do to natural predators. Thus, the threat of predation in the open field can be effectively manipulated by virtue of the presence or absence of a human being. If there are sex differences in antipredatory reactions, then one can expect that (other conditions being equal) manipulations of the predatory overtones of the open-field situation may result in variations in the strength of the sex differences. However, considering the results of Experiment 1 , we expected that enhanced predatory over-

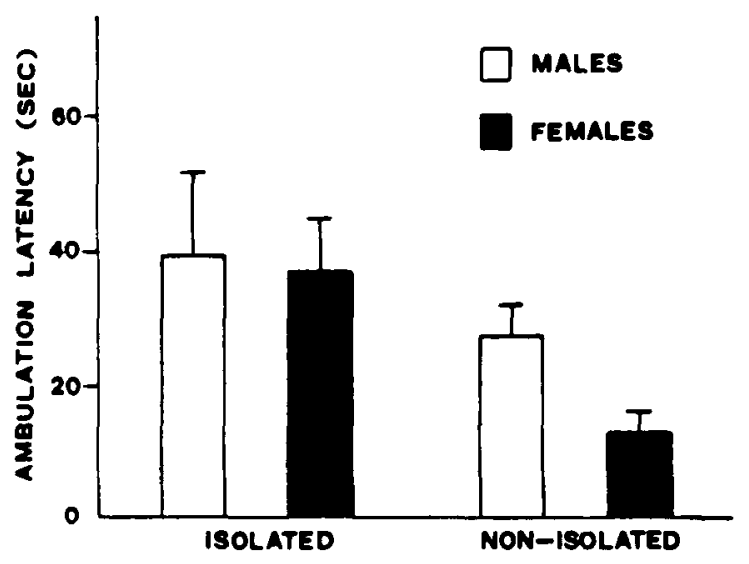

Figure 1. Mean ambulation latencies of nonisolated chicks and of chicks isolated for 2 days prior to testing. 


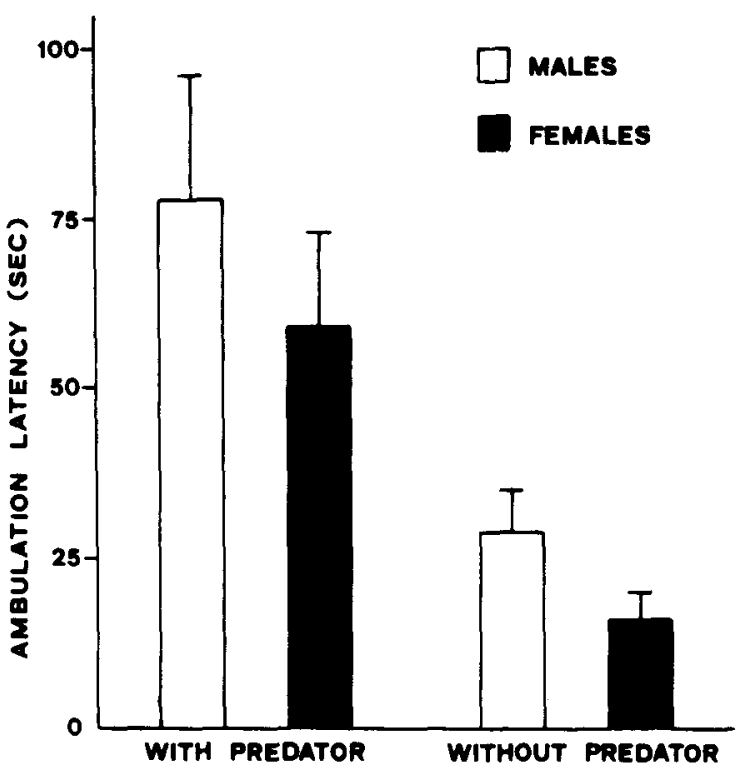

Figure 2. Mean ambulation latencies of chicks tested in the presence or in the absence of a visible human as a predator.

tones would produce increased ambulation latencies in both males and females without modifying sex differences.

\section{Method}

Subjects. Twenty male and 20 female 10-day-old chicks were used. Strain and rearing conditions were the same as in the previous experiment. All animals were socially reared in groups of 10 until tested.

Apparatus and Procedure. The apparatus and general procedure were the same as in the previous experiment. Twenty chicks ( 10 males and 10 females) were tested in the presence of a human being (i.e., the experimenter). The experimenter/predator was seated in front of and above the open field at a distance of about $90-100 \mathrm{~cm}$ from the animal. The other 20 chicks ( 10 males and 10 females) were also tested with the experimenter seated at the same distance from the apparatus, but this time a unidirectional screen allowed the experimenter to see the chick without being seen by it. The experimenter was unaware of the sex of the animals tested. Latencies of ambulation were measured as in the previous experiment.

\section{Results}

The results are illustrated in Figure 2. A $\log (x+1)$ transformation was performed to minimize heterogeneity of variance. A subsequent $2 \times 2$ analysis of variance revealed that the main effect of testing conditions $[F(1,36)$ $=26.64, p<.001]$ and the main effect of sex $[F(1,36)$ $=4.59, p=.0368]$ were significant, although their interaction was not statistically significant $[F(1,36)=1.09$, $p=.30]$. Thus, the presence of a visible predator increased predator-evasion responses of chicks, but sex differences remained unchanged.

\section{DISCUSSION}

Sex differences in the open-field behavior of chicks seem to be reducible to one simple effect: differences in motivation for social reinstatement. If the behavior of chicks in an open field is a compromise between tendencies to reinstate social contact with imprinted companions and to minimize detection in the face of possible predation, then one can suppose that antipredatory reactions would be shorter if motivation to reinstate social contact were stronger. The results of Experiments 1 and 2 confirm this hypothesis: there were no differences in antipredatory reactions between males and females, but there were differences in the need for social reinstatement. In fact, when the motivation for social reinstatement was abolished through habituation to social isolation, males and females did not differ in the antipredatory reaction (i.e., in terms of the duration of freezing). Also, the presence of a visible predator in Experiment 2 increased ambulation latencies as expected, but did not affect sex differences. The reason for this is simple: Adding predatory overtones to the open-field testing situation does not affect the substantial social-need difference between males and females; social separation from cage companions is more stressful for females than for males.

It is worth noting that the hypothesis whereby sex differences merely reflect a difference in the level of "fear," with its corollary that sex differences appear only at lowto-moderate fear levels (see introduction), proves difficult to reconcile with these results. Indeed, the presence of a predator should increase fear levels, and therefore sex differences should disappear. Experiment 2, however, showed that this is not the case: Although ambulation latencies did, indeed, increase in chicks tested with a predator, sex differences remained unchanged.

From a theoretical point of view, a major difficulty with the general "emotionality" or "fear" interpretation of open-field behavior is that it does not allow for a clear functional interpretation of these sex differences. On the other hand, Gallup and Suarez's (1980) hypothesis sounds very reasonable from an ethological point of view. The further conjecture that threats of predation and social isolation may be of differing importance for males and females also fits in well with observations on the behavior of chickens under natural conditions. In feral populations, dominant cocks maintain and patrol a large territory within which a number of females live (McBride, Parer, \& Foenander, 1969). Thus, territoriality can favor social contact in females and social dispersion and aggressive behavior in males. Open-field behavior of chicks, therefore, reflects the different adaptive strategies this species has developed in its natural niche rather than emotionality differences exhibited in highly unnatural laboratory situations.

\section{REFERENCES}

Candland, D. K., Nagy, Z. M., \& Conklyn, L. D. H. (1963). Emotional behavior in the domestic chicken (White Leghorn) as a function of age and developmental environment. Joumal of Comparative \& Physiological Psychology, 56, 1069-1073.

FAURE, J. M. (1979). Influence de la souche et du sexe sur le com- 
portement en open-field du jeune poussin. Biology of Behaviour, 4, 19-24.

FAUre, J. M., Folmer, J. C. (1975). Etude génétique de l'activité précoce en open-field du jeune poussin. Annales de Génétique et de Selection Animale, 7, 123-132.

GALLUP, G. G., JR. (1974). Genetic influence on tonic immobility in chickens. Animal Leaming \& Behavior, 2, 145-147.

Gallup, G. G., JR., SuArez, S. D. (1980). An ethological analysis of open-field behaviour in chickens. Animal Behaviour, 28, 368-378.

Jones, R. B. (1977a). Repeated exposure of the domestic chick to a novel environment. Effects on behavioural responses. Behavioural Processes, 2, 315-323.

JoNEs, R. B. (1977b). Sex and strain differences in the open-field responses of the domestic chick. Applied Animal Ethology, 3, 255-261.

JoNes, R. B. (1979). The hole-in-the-wall test: Its validity as a measure of the "timidity" aspect of fear in the domestic chick. IRCS Medical Science, 7, 167

JONES, R. B., BLACK, A. J. (1979). The behaviour of domestic chicks in their home cages and in an open-field: Substrate effects. IRCS Medical Science, 7, 619.

Jones, R. B., \& FAURE, J. M. (1981). Sex effects on open-field behaviour in the domestic chick as a function of age. Biology of Behaviour, 6, 265-272.

JONES, R. B., FAURE, J. M. (1982). Open-field behaviour of male and female domestic chick as a function of housing conditions, test situations and novelty. Biology of Behaviour, 7, 17-25.

McBrine, G., FoenANDER, F. (1962). Territorial behaviour in flocks of domestic fowls. Nature, 194, 102.
McBride, G., PArer, I. P., Foenander, F. (1969). The social organization and behaviour of the feral domestic fowl. Animal Behaviour Monograph, 2, 127-181.

Suarez, S. D. * Gallup, G. G., Jr. (1981). Predatory overtones of open-field testing in chickens. Animal Learning \& Behavior, 9, 153-163.

SuArez, S. D., \& Gallup, G. G., Jr. (1982). Open-field behavior in chickens: The experimenter is a predator. Journal of Comparative \& Physiological Psychology, 96, 432-439.

SuAREZ, S. D., GAlluP, G. G., JR. (1983). Social reinstatement and open-field testing in chickens. Animal Learning \& Behavior, 11, 119-126.

SuArez, S. D., \& Gallup, G. G., JR. (1985). Open-field behaviour in chickens: A replication revisited. Behavioural Processes, 10, 333-340.

\section{NOTE}

1. In this particular strain of chicks, the gender cannot be detected at first sight. Males and females can be distinguished by carefully examining the length and arrangement of the wing feathers. Animals were sexed by an independent expert observer and placed in the stabulation cages according to a particular code before the beginning of the experiment, so that the experimenters did not know the sex of any animal during testing.

(Manuscript received August 10, 1987; revision accepted for publication January 11,1988 .) 